Pacific Journal of Mathematics

LOCALLY UNIVALENT FUNCTIONS AND COEFFICIENT 


\title{
LOCALLY UNIVALENT FUNCTIONS AND COEFFICIENT DISTORTIONS
}

\author{
H. Silverman, E. M. Silvia, \\ AND D. N. TELAGE
}

\begin{abstract}
We look at functions $f(z)=z+\sum_{n=2}^{\infty} a_{n} z^{n}$ satisfying $\sum_{n=2}^{\infty} n\left|a_{n}\right|>1$ and determine conditions for which the arguments of the coefficients may vary without affecting the univalence of the function. A bound on the radius of starlikeness for the convolution of functions taken from the closed convex hull of convex functions and a special subclass of starlike functions is also obtained.
\end{abstract}

1. Introduction. Let $L S$ denote the class of functions of the form $z+\sum_{n=2}^{\infty} a_{n} z^{n}$ that are analytic and locally univalent in the unit disk $U$, and let $S$ denote the subclass of univalent functions. It is well known that a sufficient condition for $z+\sum_{n=2}^{\infty} a_{n} z^{n}$ to be in $S$ is that

$$
\sum_{n=2}^{\infty} n\left|a_{n}\right| \leqq 1
$$

For functions of the form

$$
z-\sum_{n=2}^{\infty}\left|a_{n}\right| z^{n}
$$

the condition (1) is also necessary. This follows because functions that fail to satisfy (1) are not even in $L S$. The necessary and sufficient condition (1) for functions of the form (2) to be in $S$ makes extremal problems much more manageable. Very little is known for functions in $S$ of the form

$$
f_{\lambda}(z)=z-e^{i \lambda} \sum_{n=2}^{\infty}\left|a_{n}\right| z^{n},
$$

where the coefficients are not necessarily real but have constant argument. In [6] it is asked if a function $g(\lambda, n)$ can be found for which the inequality $\left|a_{n}\right| \leqq g(\lambda, n)$ is sharp. Note that $g(0, n)=1 / n$ and $g(\pi, n)=n$, with extremal functions $z-z^{n} / n$ and $z /(1-z)^{2}$ respectively.

In this paper we show that a function in $L S$ must satisfy (1) when its coefficients are "close to" negative. Since the degree of closeness depends on both $\lambda$ and the coefficients in (3), rather than on $\lambda$ alone, we cannot conclude that $g(\lambda, n) \leqq 1 / n$ for any positive $\lambda$. We also examine the extent to which a violation of condition (1) 
enables us to distort the arguments of some of the coefficients to construct functions that are not in $L S$.

The Hadamard product or convolution of two power series $f(z)=$ $\sum_{n=0}^{\infty} a_{n} z^{n}$ and $g(z)=\sum_{n=0}^{\infty} b_{n} z^{n}$ is defined as the power series $(f * g)(z)=$ $\sum_{n=0}^{\infty} a_{n} b_{n} z^{n}$. For

$$
h_{\lambda}(z)=z+e^{i \lambda} \sum_{n=2}^{\infty} z^{n},
$$

we may express (3) as $f_{0} * h_{\lambda}$. When $\lambda$ is sufficiently small $h_{\lambda}(z)$ is starlike and we find a bound on the radius of starlikeness for $h_{2} * f$, where $\operatorname{Re} f(z) / z>1 / 2(z \in U)$. This generalizes a result of MacGregor [4].

2. Coefficient distortions. Given a function $f(z)=z+\sum_{n=2}^{\infty} b_{n} z^{n}$, the function $g(z)=z+\sum_{n=2}^{\infty} e^{i \lambda_{n}} b_{n} z^{n}$ is said to be in $F_{\varepsilon}(f)$ for some $\varepsilon>0$ if $-\varepsilon \leqq \lambda_{n} \leqq \varepsilon$ for all $n$.

LEMma 1. If $f(z)=z+\sum_{n=2}^{\infty} b_{n} z^{n} \notin L S$, then there exists an $\varepsilon>0$ such that $g \in F_{\varepsilon}(f)$ implies that $g \notin L S$.

Proof. Suppose, on the contrary, that there is a sequence $\varepsilon(n)$ tending to 0 for which we can find a corresponding sequence of functions $g_{n} \in F_{\varepsilon(n)}$ such that $g_{n} \in L S$ for all $n$. Since $f \notin L S$, there exists a point $z_{0} \in U$ such that $f^{\prime}\left(z_{0}\right)=0$. Note that $\left\{g_{n}^{\prime}\right\}$ converges uniformly to $f^{\prime}$ in some neighborhood $D$ of $z_{0}$. Since $g_{n}^{\prime} \neq 0$ in $D$ for any $n$, it follows by Hurwitz's theorem that $f^{\prime} \neq 0$ in $D$. This contradicts our assumption that $f^{\prime}\left(z_{0}\right)=0$.

THEOREM 1. If $f(z)=z-\sum_{n=2}^{\infty}\left|a_{n}\right| z^{n}$ with $\sum_{n=2}^{\infty} n\left|a_{n}\right|>1$, then there exists an $\varepsilon>0$ such that $g \in F_{\varepsilon}(f)$ implies that $g \notin L S$.

Proof. Since $f^{\prime}(0)=1$ and $f^{\prime}(r)<0$ for $r(<1)$ sufficiently close to 1 , there must exist a point $r_{0}, 0<r_{0}<1$, such that $f^{\prime}\left(r_{0}\right)=0$. The result now follows from the lemma, with $b_{n}=-\left|a_{n}\right|$.

CoRollaRY. If $\sum_{n=2}^{\infty} n\left|a_{n}\right|>1$, then $f_{\lambda}(z)$, defined by (3), is not in LS for $\lambda$ sufficiently small.

Our next theorem shows that if (1) is violated, then we can always construct a nonunivalent function by distorting the arguments of finitely many coefficients.

THEOREM 2. If $\sum_{n=2}^{N} n\left|a_{n}\right|>1$, then there exist real numbers $\alpha_{2}, \cdots, \alpha_{N}\left(-\pi<\alpha_{j} \leqq \pi\right)$ such that 


$$
f(z)=z+\sum_{n=2}^{N} a_{n} e^{i \alpha_{n}} z^{n}+\sum_{n=N+1}^{\infty} a_{n} z^{n} \notin L S
$$

Proof. Let $C=z(t)$ be an arc of increasing modulus from the origin to the boundary of $U$ such that

$$
g(z)=\sum_{n=N+1}^{\infty} n a_{n} z^{n-1} \leqq 0 \quad \text { for } \quad z \in C
$$

For each point $z=z(t) \in C,|z|=r$, choose $\alpha_{n}(t)$ so that

$$
n a_{n} e^{i \alpha_{n}(t)} z^{n-1}=-n\left|a_{n}\right| r^{n-1} \quad(n=2, \cdots, N) \text {. }
$$

Next define $f_{t}(z)$ by

$$
f_{t}(z)=z+\sum_{n=2}^{N} a_{n} e^{i \alpha_{n}(t)} z^{n}+\sum_{n=N+1}^{\infty} a_{n} z^{n}
$$

where $\alpha_{n}(t)$ varies continuously with $t$. Since $g(z) \leqq 0$ for $z \in C$, $|z|=r$, we have for all $t$ that

$$
f_{t}^{\prime}(z) \leqq 1-\sum_{n=2}^{N} n\left|a_{n}\right| r^{n-1} \quad(z \in C)
$$

Since $f_{t}^{\prime}(0)=1$ and $f_{t}^{\prime}(z)<0$ for $z \in C$ sufficiently close to the boundary of $U$, it follows for some $\xi=z\left(t_{0}\right)$ on $C$ that $f_{t_{0}}^{\prime}(\xi)=0$. Setting $f(z)=f_{t_{0}}(z)$ and $\alpha_{n}=\alpha_{n}\left(t_{0}\right)$, the result follows.

COROLLARY 1. If $\sum_{n=2}^{N} n\left|a_{n}\right|>1$, then there exist real numbers $\alpha_{2}, \cdots, \alpha_{N}\left(-\pi<\alpha_{j} \leqq \pi\right)$ and an $\varepsilon>0$ such that for each $\lambda,-\varepsilon \leqq$ $\lambda \leqq \varepsilon$,

$$
f_{\lambda}(z)=z+e^{i \lambda}\left(\sum_{n=2}^{N} a_{n} e^{i \alpha_{n}} z^{n}+\sum_{n=N+1}^{\infty} a_{n} z^{n}\right) \notin L S
$$

Proof. The corollary is established upon applying Lemma 1 to Theorem 2.

COROLLARY 2. If $\sum_{k=2}^{N} n_{k}\left|a_{n_{k}}\right|>1$, then there exist real numbers $\alpha_{2}, \cdots, \alpha_{N}\left(-\pi<\alpha_{j} \leqq \pi\right)$ and $\varepsilon>0$ such that for each $\lambda,-\varepsilon \leqq \lambda \leqq \varepsilon$,

$$
f_{\lambda}(z)=z+e^{i \lambda}\left(\sum_{k=2}^{N} a_{n_{k}} e^{i \alpha_{k}} z^{n_{k}}+\sum_{\substack{n=2 \\ n \neq n_{k}}}^{\infty} a_{n} z^{n}\right) \notin L S .
$$

Proof. The proof is the same as that of Corollary 1 except for a rearrangement of terms.

3. Extremal examples. One might ask for conditions under which $\sum_{n=2}^{\infty} n\left|a_{n}\right|>1$ guarantees the existence of a real number $\lambda$ 
such that $f_{\lambda}(z)=z+e^{i \lambda} \sum_{n=2}^{\infty} a_{n} z^{n} \notin S$. Before answering this question, we need

Lemma 2. For $n \geqq 3$ there exist real numbers $\alpha_{1}, \alpha_{2}, \cdots, \alpha_{n}$ such that $\left|\sum_{k=1}^{n} e^{i \alpha_{k}} z^{k}\right|<n(|z| \leqq 1)$.

Proof. We have $\left|\sum_{k=1}^{n} e^{i \alpha_{k}} e^{i k \theta}\right|=n$ if and only if there is a $\theta$ for which

$$
\alpha_{1}+\theta=\alpha_{l c}+k \theta \quad(\bmod 2 \pi), \quad k=2, \cdots, n .
$$

Clearly the $\alpha_{k}$ 's can be chosen to preclude the existence of such a $\theta$.

THEOREM 3. (i) If $\sum_{k=2}^{3} n_{k}\left|a_{n_{k}}\right|>1$, then $f_{\lambda}(z)=z+e^{i \lambda}\left(a_{n_{2}} z^{n_{2}}+\right.$ $\left.a_{n_{3}} z^{n_{3}}\right) \notin L S$ for some $\lambda$.

(ii) If $N>3$, then we can find $\left\{a_{n_{k}} \mid k=2,3, \cdots, N\right\}$ such that $\sum_{k=2}^{N} n_{k}\left|a_{n_{k}}\right|>1$ and $f_{\lambda}(z)=z+e^{i \lambda} \sum_{k=2}^{N} a_{n_{k}} z^{n_{k}} \in S$ for all $\lambda$.

Proof. To prove (i), assume arg $a_{n_{2}}=\alpha_{2}+\pi$ and $\arg a_{n_{3}}=\alpha_{3}+\pi$. Then for $\theta=\left(\alpha_{2}-\alpha_{3}\right) /\left(n_{3}-n_{2}\right)$, we have

$$
f_{2}^{\prime}\left(r e^{i \theta}\right)=1-e^{i \lambda}\left(n_{2}\left|a_{n_{2}}\right| r^{n_{2}-1}+n_{3}\left|a_{n_{3}}\right| r^{n_{3}-1}\right) e^{i \beta},
$$

where

$$
\beta=\alpha_{2}+\frac{\left(n_{2}-1\right)\left(\alpha_{2}-\alpha_{3}\right)}{n_{3}-n_{2}}
$$

Hence $f_{\lambda}(z) \notin L S$ for $\lambda=-\beta$.

To prove (ii), we choose $\left\{\alpha_{k}\right\}$ so that

$$
\left|\sum_{k=2}^{N} e^{i \alpha_{k}} z^{n_{k}-1}\right| \leqq A<N-1 \quad(|z| \leqq 1) .
$$

For $1<B \leqq(N-1) / A$, set

$$
f_{\lambda}(z)=z+e^{i \lambda} \sum_{k=2}^{N} \frac{B e^{i \alpha_{k}}}{(N-1) n_{k}} z^{n_{k}}
$$

Then

$$
f_{\lambda}^{\prime}(z)=1+\frac{B}{N-1} e^{i \lambda} \sum_{k=2}^{N-1} e^{i \alpha_{k}} z^{n_{k}-1},
$$

so that

$$
\operatorname{Re} f_{\lambda}^{\prime}(z) \geqq 1-\frac{B}{N-1}\left|\sum_{k=2}^{N-1} e^{i \alpha_{k}} z^{n_{k}-1}\right|>1-\frac{A B}{N-1} \geqq 0 \quad(z \in U) .
$$


By a criterion of Kaplan [3], $f_{\lambda}(z) \in S$ for all $\lambda$.

4. A radius of starlikeness theorem. Denote by $F$ functions of the form $f(z)=z+\sum_{n=2}^{\infty} a_{n} z^{n}$ that are analytic in $U$ and satisfy $\operatorname{Re} f(z) / z>1 / 2$. MacGregor has shown [4] that the radius of starlikeness of $F$ is $1 / \sqrt{2}$. In this section we generalize this result. It is known [1] that the family $F$ is the closed convex hull of convex functions, and that a function $f(z)$ is in $F$ if and only if it can be expressed as

$$
f(z)=\int_{X} \frac{z}{1-x z} d \mu(x)
$$

for some probability measure $\mu$ defined on the unit circle $X$.

In [2] Campbell proves

LEMMA A. Let $M$ be a class of starlike functions with $b(r)=$ $\max \{\arg f(z) / z:|z|=r, f \in M\} . \quad$ If $\left|z\left(f^{\prime}(z) / f(z)\right)-a(r)\right| \leqq d(r)$ for $f \in M$, where $a(r)$ and $d(r)$ are continuous functions of $r$ satisfying $\lim _{r \rightarrow 1} a(r) / d(r)>0$, then the radius of starlikeness of the closed convex hull of $M$ is at least as large as the first positive root of $a(r)$ $d(r) \sec b(r)=0$.

In the sequel, we let

$$
H_{\varepsilon}=\left\{z+e^{i \lambda} \sum_{n=2}^{\infty} z^{n}|| e^{i \lambda}-1 \mid \leqq \varepsilon<1\right\}
$$

and

$$
G_{\varepsilon}=\left\{\frac{h(x z)}{x}\left|h \in H_{\varepsilon},\right| x \mid=1\right\} .
$$

We shall also need

LEMMA 3. Set $a(r)=1 /\left(1-r^{2}\right)-\varepsilon^{2} r^{2} /\left(1-\varepsilon^{2} r^{2}\right)$ and $d(r)=r /\left(1-r^{2}\right)+$ $\varepsilon r /\left(1-\varepsilon^{2} r^{2}\right)$. For $g \in G_{\varepsilon}$, the values for $\left(z g^{\prime}(z) / g(z)\right),|z| \leqq r$, lie in $a$ disk centered at $a(r)$ and having radius $d(r)$.

Proof. It suffices to prove the result for $h \in H_{\varepsilon}$ since the class $G_{\varepsilon}$ consists of rotations of these functions. Writing $h(z)=$ $\left(z+\left(e^{i \lambda}-1\right) z^{2}\right) /(1-z)$ for $h \in H_{\varepsilon}$, we see that $z h^{\prime}(z) / h(z)=1 /(1-z)+$ $\left(\left(e^{i \lambda}-1\right) z\right) /\left(1+\left(e^{i \lambda}-1\right) z\right)$. Since

$$
\frac{-\varepsilon r}{1-\varepsilon r} \leqq \operatorname{Re} \frac{\left(e^{i \lambda}-1\right) z}{1+\left(e^{i \lambda}-1\right) z} \leqq \frac{\varepsilon r}{1+\varepsilon r} \quad(|z| \leqq r),
$$

it follows that 


$$
\frac{1}{1+r}-\frac{\varepsilon r}{1-\varepsilon r} \leqq \operatorname{Re} \frac{z h^{\prime}(z)}{h(z)} \leqq \frac{1}{1-r}+\frac{\varepsilon r}{1+\varepsilon r} .
$$

Thus the values for $z h^{\prime}(z) / h(z)$ are contained in a disk centered at

$$
\frac{1}{2}\left[\left(\frac{1}{1-r}+\frac{\varepsilon r}{1+\varepsilon r}\right)+\left(\frac{1}{1+r}-\frac{\varepsilon r}{1-\varepsilon r}\right)\right]=a(r)
$$

whose radius is

$$
\frac{1}{2}\left[\left(\frac{1}{1-r}+\frac{\varepsilon r}{1+\varepsilon r}\right)-\left(\frac{1}{1+r}-\frac{\varepsilon r}{1-\varepsilon r}\right)\right]=d(r) .
$$

Lemma 4. A function $g \in G_{\varepsilon}$ defined by (7) is starlike if and only if $\varepsilon \leqq 1 / 3$.

Proof. It suffices to consider $h \in H_{\varepsilon}$ defined by (6). Letting $r \rightarrow 1$ in the left-hand side of $(8)$, we see that $\operatorname{Re} z h^{\prime}(z) / h(z) \geqq 0$ when $\varepsilon \leqq 1 / 3$. For $e^{i \lambda}-1=\varepsilon e^{i \sigma}$ and $\beta=\pi-\sigma$, we have $e^{i \beta} h^{\prime}\left(e^{i \beta}\right) / h\left(e^{i \beta}\right)=$ $1 / 2-\varepsilon /(1-\varepsilon)<0$ when $\varepsilon>1 / 3$.

REMARK. Since the Pólya-Schoenberg conjecture is true [5], we know that for $f$ convex and $h \in H_{\varepsilon}(\varepsilon \leqq 1 / 3)$, the Hadamard product $h * f$ is starlike. However if $f$ is only required to be starlike, then $h_{\lambda} * f$ need not be in $S$ for any $h_{\lambda}$ defined by (4), $\lambda \neq 0$. To see this, observe that $h_{\lambda} * z /\left((1-z)^{2}\right)=z+e^{i \lambda} \sum_{n=2}^{\infty} n z^{n}$ is not in $S$ for $\lambda \neq 0$ because $f(z)=z+\sum_{n=2}^{\infty} a_{n} z^{n},\left|a_{2}\right|=2$, is in $S$ only if $f(z)=$ $z /\left((1-x z)^{2}\right),|x|=1$.

We now give a bound for the radius of starlikeness for $h * f$, $f \in F, h \in H_{\varepsilon}$ with $\varepsilon \leqq 1 / 3$.

THEOREM 4. Suppose $h(z)=z+e^{i \lambda} \sum_{n=2}^{\infty} z^{n} \in H_{\varepsilon}, \quad \varepsilon \leqq 1 / 3$, and $f \in F$, with $a(r)$ and $d(r)$ defined in Lemma 3. Then $h * f$ is starlike in a disk $|z|<r_{0}$, where $r_{0}$ is the first positive root of

$$
a(r)-\frac{d(r)}{\sqrt{\left(1-\varepsilon^{2} r^{2}\right)\left(1-r^{2}\right)}-\varepsilon r^{2}}=0 .
$$

Proof. In view of (5),

$$
(h * f)(z)=\int_{X} h * \frac{z}{1-x z} d \mu(x)=\int_{X} \frac{h(x z)}{x} d \mu(x), \quad|x|=1 .
$$

By Lemma 4, the kernel functions are all starlike. An application of Lemma 3 to Lemma A shows that $h * f$ is starlike in a disk whose radius is at least as large as the first positive root of 


$$
a(r)-d(r) \sec b(r)=0,
$$

where

$$
b(r)=\max _{|z|=r}\left\{\arg \frac{g(z)}{z} \mid g \in G_{\varepsilon}\right\}
$$

Since

$$
\begin{aligned}
b(r) & \leqq \max _{|z|=r}|\arg (1+\varepsilon z)|+\max _{|z|=r}|\arg (1-z)| \\
& =\sin ^{-1}(\varepsilon r)+\sin ^{-1}(r)=t(r),
\end{aligned}
$$

A substitution of the right-hand side of (11) into (10) yields the desired result.

REMARK. If $\varepsilon=0$ then (9) reduces to $1 /\left(1-r^{2}\right)-r /\left(\left(1-r^{2}\right)^{3 / 2}\right)=0$, whose smallest positive root is $1 / \sqrt{2}$. This coincides with a sharp result of MacGregor [4].

\section{REFERENCES}

1. L. Brickman, T. H. MacGregor and D. R. Wilkin, Convex hulls of some classical families of univalent functions, Trans. Amer. Math. Soc., 156 (1971), 91-107.

2. D. M. Campbell, A survey of properties of the convex combination of univalent functions, Rocky Mt. J. Math., 5 (1974), 475-492.

3. W. Kaplan, Close-to-convex schlicht functions, Michigan J. Math., 1 (1952), 169-185.

4. T. H. MacGregor, The radius of convexity for starlike functions of order 1/2, Proc. Amer. Math. Soc., 14 (1963), 71-76.

5. St. Ruscheweyh and T. Sheil-Small, Hadamard products of schlicht functions and the Pólya-Schoenberg conjecture, Comm. Math. Helv., 48 (1973), 119-135.

6. H. Silverman, Univalent functions with negative coefficients, Proc. Amer. Math. Soc., 51 (1975), 109-116.

Received July 15, 1977 and in revised form November 16, 1977. This work was completed while the first two authors were visiting at the University of Kentucky. The research of the first author was partially supported by a College of Charleston Summer Research Grant. The second author was on a sabbatical leave from the University of California, Davis.

College of Charleston

Charleston, SC 29401

UNIVERSITY OF CALIFORNIA

DAVIS, CA 95616

AND

UNIVERSITY OF KENTUCKY

LeXiNGTON, KY 40506 



\title{
PACIFIC JOURNAL OF MATHEMATICS
}

\section{EDITORS}

RICHARD ARENS (Managing Editor)

University of California

Los Angeles, CA 90024

Charles W. Curtis

University of Oregon

Eugene, OR 97403

C. C. MOORE

University of California

Berkeley, CA 94720
J. DUGUNDJI

Department of Mathematics

University of Southern California

Los Angeles, CA 90007

R. Finn and J. Milgram

Stanford University

Stanford, CA 94305

\section{ASSOCIATE EDITORS}
E. F. BECKENBACH
B. H. Neumann
F. WOLF
K. YosHidA

\section{SUPPORTING INSTITUTIONS}

\author{
UNIVERSITY OF BRITISH COLUMBIA \\ CALIFORNIA INSTITUTE OF TECHNOLOGY \\ UNIVERSITY OF CALIFORNIA \\ MONTANA STATE UNIVERSITY \\ UNIVERSITY OF NEVADA, RENO \\ NEW MEXICO STATE UNIVERSITY \\ OREGON STATE UNIVERSITY \\ UNIVERSITY OF OREGON
}

\author{
UNIVERSITY OF SOUTHERN CALIFORNIA \\ STANFORD UNIVERSITY \\ UNIVERSITY OF HAWAII \\ UNIVERSITY OF TOKYO \\ UNIVERSITY OF UTAH \\ WASHINGTON STATE UNIVERSITY \\ UNIVERSITY OF WASHINGTON
}

The Supporting Institutions listed above contribute to the cost of publication of this Journal, but they are not owners or publishers and have no responsibility for its content or policies.

Mathematical papers intended for publication in the Pacific Journal of Mathematics should be in typed form or offset-reproduced, (not dittoed), double spaced with large margins. Please do not use built up fractions in the text of the manuscript. However, you may use them in the displayed equations. Underline Greek letters in red, German in green, and script in blue. The first paragraph or two must be capable of being used separately as a synopsis of the entire paper. Items of the bibliography should not be cited there unless absolutely necessary, in which case they must be identified by author and journal, rather than by item number. Manuscripts, in triplicate, may be sent to any one of the editors. Please classify according to the scheme of Math. Reviews, Index to Vol. 39. All other communications should be addressed to the managing editor, or Elaine Barth, University of California, Los Angeles, California, 90024.

50 reprints to each author are provided free for each article, only if page charges have been substantially paid. Additional copies may be obtained at cost in multiples of 50 .

The Pacific Journal of Mathematics is issued monthly as of January 1966. Regular subscription rate: $\$ 72.00$ a year (6 Vols., 12 issues). Special rate: $\$ 36.00$ a year to individual members of supporting institutions.

Subscriptions, orders for numbers issued in the last three calendar years, and changes of address should be sent to Pacific Journal of Mathematics, P.O. Box 969, Carmel Valley, CA 93924, U.S.A. Older back numbers obtainable from Kraus Periodicals Co., Route 100, Millwood, NY 10546.

PUBLISHED BY PACIFIC JOURNAL OF MATHEMATICS, A NON-PROFIT CORPORATION

Printed at Kokusai Bunken Insatsusha (International Academic Printing Co., Ltd.). 8-8, 3-chome, Takadanobaba, Shinjuku-ku, Tokyo 160, Japan.

Copyright (C) 1978 by Pacific Journal of Mathematics Manufactured and first issued in Japan 


\section{Pacific Journal of Mathematics}

Vol. 77, No. $2 \quad$ February, 1978

Graham Donald Allen, Duals of Lorentz spaces ................... 287

Gert Einar Torsten Almkvist, The number of nonfree components in the decomposition of symmetric powers in characteristic p .......... 293

John J. Buoni and Bhushan L. Wadhwa, On joint numerical ranges ...... 303

Joseph Eugene Collison, Central moments for arithmetic functions . . . . . . 307

Michael Walter Davis, Smooth G-manifolds as collections of fiber

bundles ........................................ 315

Michael E. Detlefsen, Symmetric sublattices of a Noether lattice......... 365

David Downing, Surjectivity results for $\phi$-accretive set-valued

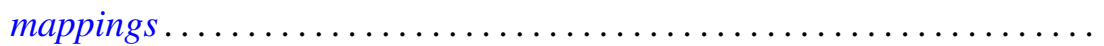

David Allyn Drake and Dieter Jungnickel, Klingenberg structures and partial designs. II. Regularity and uniformity ................. 389

Edward George Effros and Jonathan Rosenberg, $C^{*}$-algebras with approximately inner flip .......................... 417

Burton I. Fein, Minimal splitting fields for group representations. II. . . . . 445

Benjamin Rigler Halpern, A general coincidence theory ............. 451

Masamitsu Mori, A vanishing theorem for the mod $p$ Massey-Peterson spectral sequence ................................ 473

John C. Oxtoby and Vidhu S. Prasad, Homeomorphic measures in the

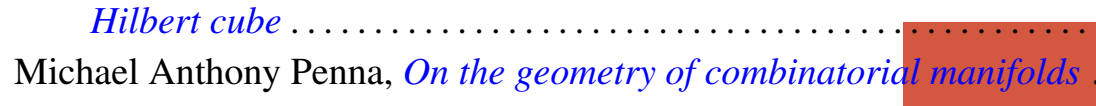

Robert Ralph Phelps, Gaussian null sets and differentiability of Lipschitz map on Banach spaces........................

Herbert Silverman, Evelyn Marie Silvia and D. N. Telage, Locally univalent functions and coefficient distortions...

Donald Curtis Taylor, The strong bidual of $\Gamma(K)$

Willie Taylor, On the oscillatory and asymptotic behavior of solutions of fifth order selfadjoint differential equations ...........

Fu-Chien Tzung, Sufficient conditions for the set of Hausdorff compactifications to be a lattice. 